Review Article

\title{
A Systematic Review on Mucormycosis in Corona Patients and its Treatment in India
}

\author{
SRehan Ahmad', Pritha Ghosh ${ }^{2}$
}

${ }^{1}$ Assistant Professor, Department of Zoology, HMM College for Women, Kolkata, India.

${ }^{2}$ Research Scholar, Raiganj University, Raiganj, West Bengal, India.

DOI: https://doi.org/10.24321/0019.5138.202163

\section{I $\quad \mathbf{N} \quad \mathbf{F} \quad \mathbf{O}$}

\section{Corresponding Author:}

S Rehan Ahmad, Department of Zoology, HMM

College for Women, Kolkata, India

E-mail Id:

zoologist.rehan@gmail.com

Orcid Id:

https://orcid.org/0000-0003-0796-5238

How to cite this article:

Ahmad SR, Ghosh P. A Systematic Review on Mucormycosis in Corona Patients and its Treatment in India. J Commun Dis. 2021;53(3):236243.

Date of Submission: 2021-07-13

Date of Acceptance: 2021-09-25

\section{$\begin{array}{llllllll}\mathbf{A} & \mathbf{B} & \mathbf{S} & \mathbf{T} & \mathbf{R} & \mathbf{A} & \mathbf{C} & \mathbf{T}\end{array}$}

Several cases of mucormycosis infection are being reported from almost all states of India currently. Mucormycosis infection is rare but fatal. It is strongly associated with COVID- 19 as a secondary infection and increases the severity of COVID-19 infection. Fungi under Mucorales order are responsible for mucormycosis infection condition, especially people with a weak immune system and under steroid-based medication and antibiotic treatment are more vulnerable. COVID- 19 infected patients with associated risk factors like diabetes mellitus, neutropenia, diabetic ketoacidosis, organ transplant, cancer, AIDS, weak immunity, autoimmune disorders are more prone tosecondary opportunistic pathogenic infections. Special care and continuous monitoring process should be initiated as early as possible to prevent any kind of secondary fungal infections during COVID-19 infection. Though preventive strategies like antifungal therapy, and surgical debridement are present yetthemortality rate is very high in mucormycosis infection. Moreover, this current study is a brief summary of the current status, pathogenesis, management strategies, and latest guidelines for mucormycosis infection during the pandemic of coronavirusdisease 2019. Several treatment strategies like drugs, surgery, and other proper methods in hospital setups are also mentioned elaborately in this study. Appropriate doses, administration route and duration as well as reported cases of mucormycosis infection from different parts of India are also clearly documented here.

Keywords: Black Fungus, Mucormycosis, COVID-19, Comorbidity of Diabetes, Treatment of Black Fung

\section{Introduction}

Mucormycetes is one kind of fungus that is responsible for mucormycosis. Mucormycosis is also known as zygomycosis and black fungus and it comes under Mucorales order. Mucor and Rhizopus species are mostly responsible for mucormycosis. Apart from those strains, many other species like Syncephalastrum, Rhizomucor, Apophysomyces,
Cunninghamellabertholletiae, Saksenaea, Lichtheimia are also responsible for mucormycosis. ${ }^{6}$ Once Microbiology department of Velammal Medical College Hospital conducted a4 years study with 38 mucormycosispatients. The study identified fungus species including Rhizopusoryzae,Apophysomycesvariabilis, Lichtheimiacorymbifera, Mucor spp which were mainly responsible for mucormycosis. ${ }^{31} \mathrm{Inmu}$ cormycosis, hyphae of the fungus starts growing inside and 
around the blood vessels. ${ }^{7}$ Mucormycetes are abundantly present in our surrounding environment including soil, decomposed organic matter (animal faeces, mass of decomposed matter, and leaves) and air, that's why people can't avoid this fungal infection very easily. Mucormycosis mainly occurs during the autumn and summer seasons. After inhalation of mucormycetes spores, they primarily affect the sinuses or lung of the individual and then gradually the infection spreads. ${ }^{6}$ This fungal infection may spread through any kind of skin injury, cuts, wounds, and burn. ${ }^{7}$ Rhinocerebralmucormycosis infection is associated with both brain and sinuses. Several other clinical forms are pulmonary mucormycosis, cutaneous mucormycosis, gastrointestinal mucormycosis, encephalic mucormycosis. ${ }^{7}$ Mucormycosis is one kind of invasive fungal sinusitis. Long term uncontrolled diabetes mellitus, haematological malignancies, iatrogenic immune-suppressed condition, organ transplantation, HIV, infection, nosocomial infection, immune suppressant drugs, history of respiratory diseases are some common risk factors and individuals with these associated risk factors are more prone togetting mucormycosis infection. ${ }^{38}$ Blackish or bloody nasal discharge, congestion, headache, nose swelling, facial pain, cheekbone pain, sinus pain, chest pain, pleural effusion, haemoptysis, severe respiratory problems, necrosis and erythema of the outer skin of the sinuses are very common signs and symptoms ofmucormycosis infection (sinus infection). Mucormycete infection can spread to the eyes causing eye swelling (accumulating fluid around eyes), ophthalmoplegia (paralysis of the eye muscles), blurry vision, vision loss, and potentially blindness. Untreated or neglected mucormycosis may reach the brain also and may develop lethargy, slurry speech, seizures, cranial neuropathies, paralysis, brain abscess, loss of consciousness and coma. ${ }^{7}$ Tissue necrosis is an important characteristic of mucormycosis which happensdue tothe invasion and thrombosis of blood vessels. ${ }^{16}$ Typical characteristics of rhinocerebralmucormycosis areheadache, sinus congestion, facial swelling in one side, necrosis on nasal bridge, and fever. Cough, shortness of breath, and chest pain are common in pulmonary mucormycosis. In cutaneous mucormycosis, ulcers, blisters, black lesions, redness, and swelling are majorly visible. Symptoms including vomiting, nausea,gastrointestinal bleeding,and abdominal pain have mostly occurred in gastrointestinal mucormycosis. ${ }^{9}$ Infiltration of mycosis into blood vessels, tissue infarction, neutrophilic infiltrate, haemorrhage, vasculitis, and thrombosis are some additional health consequences during mucormycosis. ${ }^{38}$

Recently people in India are facing COVID-19 facilitated dangerous fungal infection. Excessive use of steroids medications for the treatment of COVID-19 positive patients especially patients with diabetes mellitus might be a reason behind the spreading of black fungus infection again after the first wave of COVID-19. COVID-19 positive patients with weak immune systems are more susceptible to black fungus infection and the mortality rate of this fungal infection is nearly 50 percent. Early diagnosis and establishment of curative treatments/therapies may ensure better recovery and biopsy and antifungal therapy should be started immediately after detection of primary symptoms. ${ }^{4}$ Union Health Minister of India marked mucormycosis or 'black fungus'as a notifiable disease under the Epidemic Disease Act, 1897 on 20th May 2021. Some states and Union Territories in India including Telangana, Rajasthan, Odisha, Tamil Nadu, Gujarat, and Chandigarh have declaredmucormycosis as an epidemic. ${ }^{12}$ As per one newspaper article published on 28th May, 2021, Gujarat gets the highest position among all the states with 2859 mucormycosis cases and Maharashtra is the second highest state with at least 2770 infection cases. 768 cases, 752 cases, 744 cases, and 701 cases were detected from Andhra Pradesh, Madhya Pradesh, Telangana, and Uttar Pradesh respectively. Till 25th May, a total of 11,717 mucormycosis infection cases were reported from different states of India. ${ }^{2}$

\section{Association between COVID-1 9 and Mucormycosis Infection}

As per the latest report on 7th May 2020, more than 0.4 million COVID-19 cases were reported in India during the second wave of COVID-19and afterwards, infection cases started to decline. In this tough situation, India is facing another secondary fungal infection, known as mucormycosis infection. More mucormycosiscases have been reported in India during the second wave of COVID-19 as compared to the first wave. ${ }^{34}$ Severe acute respiratory syndrome coronavirus 2 causing COVID-19 sometimes exhibit the risk of several secondary infections including a broad spectrum of fungal and bacterial infections. Those secondary infections are more prevalent among patients with comorbidities like diabetes mellitus, pneumonia (during ventilation), and lung disease ${ }^{25}$ COVID-19 treatment medications gradually reduce lymphocytes, one type of white blood cell count in the blood. Lymphocytes can protect the human body from any kind of infection causing pathogenic microorganisms like viruses, bacteria, and parasites. So it is quite natural that decreased lymphocytes count may cause lymphopenia in COVID-19 patients, and enhance the opportunistic microbial infection possibilities. ${ }^{45}$

Patients with COVID-19 infection are more susceptible to secondary fungal infections because COVID-19 infection induces inflammatory cytokines over-expression in the patient, reduces $\mathrm{CD} 8^{+} \mathrm{T}$-helper cell and $\mathrm{CD} 4^{+} \mathrm{T}$-helper cell count and affects cell-mediated immune system of the patient. Additionally, COVID-19 positive patients in ICUs, or long hospital stays (it can be more than 50 days as well), or patients with ventilation support may increase the rapidness 
of the secondary fungal infections. Chronic usage of steroids medications during COVID-19 infection can inhibit the immune activity of the host which ensures secondary fungal infection colonisation. The secondary fungal infection is mostly detected after recovery from COVID-19 infection or in the final stages of the infection. ${ }^{38} \mathrm{~V} \mathrm{~K} \mathrm{Paul,} \mathrm{Member}$ (Health) of NitiAayog said mucor, one kind of fungus, is responsible for mucormycosis, andis commonly visible on moist surfaces. So patients who are continuously attached to wet surfaces are more susceptible to fungal infection. Dr Paul mentioned some life-saving drugs like prednisolone, dexamethasone, dexona, methylprednisolone, tocilizumab, anditolizumab for the treatment of COVID-19 which can inhibit the host's natural immunity and increase the proneness of secondary infections. ${ }^{29}$

\section{Mucormycosis Cases across India during COVID- 19 Pandemic}

In between the second wave of COVID-19, people are currently facing a new infection called "black fungus" infection across some states in India. Last year during the first wave of COVID-19, many patients were admitted to the various hospitals across states of India after getting black fungus infection and lost their vision completely due to it. ${ }^{11}$ SadanandaGowda, Union Minister of India also confirmed the estimated number of mucormycosis cases. Between 22nd May and 26th May 2021, 2,869 mucormycosis cases were enrolled. ${ }^{46}$ Till 28th May, 2021, more than 14872 mucormycosis cases were detected in India. Among all states of India, the highest number of mucormycosis cases was from Gujarat, followed by Maharashtra. At least 3726 mucormycosis infection cases were reported so far from Gujarat. To overcome this situation, various control measures are taken such as guidelines regarding mucormycosis, treatments therapies including drugs availability, special task forces, and separate setups in hospitals for infected patients. ${ }^{28,34}$ On 25th May 2021, Maharashtra health minister Mr Rajesh Tope said that Maharashtra will obtain 60,000 Amphotericin-B vials from 1st June via the government global tender for mucormycosis infection treatment. After a review meeting of the Maharashtra state regarding the mucormycosis and COVID-19 cases, Mr Rajesh Tope mentioned 2,245 mucormycosis cases in Maharashtra in his report. He added the point that among 2,245 mucormycosis cases, 1,007 will be givenfacilities of Mahatma JyotiraoPhule Jan ArogyaYojana (MJPJAY) and their total treatment expense will be free of cost. According to him, one government resolution was established by the Maharashtra government for treatment purposes, and the finance department of the Maharashtra government fixed 30 crores for the mucormycosis treatment purpose. ${ }^{2}$ Last year in Ahmedabad, mucormycosis was detected in five individuals and all five mucormycosis infected people were associated with COVID-19 infection (either admitted due to COVID-19 or recovered from COVID-19 infection). Two out of five patientshaddied due to mucormycosis and two individuals had permanently lost their vision. In Bangalore, similar kinds of four mucormycosis cases were diagnosed and two among them died in the same way. ${ }^{4}$ According to the ANI news report, within 15 days, twelve patients with mucormycosiswere admitted to Sir Ganga Ram Hospital, New Delhi In December 2020. All of them had a history of COVID-19 infection. ENT department of this hospital including Eye Surgery teams operated on 10 patients and were able to save the eyesight of only 50 percent of the patients. Also, five among twelve patients expired due to the black fungus infection. The report also concluded that black fungus infection (mucormycosis) can't transmit from person to person or from animals to people. ${ }^{44}$ As per $\mathrm{Dr}$ TatyaraoLahane, Head, Directorate of Medical Education and Research (DMER), mucormycosis cases are rising in India and till date, eight infected patients among 200 mucormycosis infected patients have expired in different locations of the Maharashtra state. He mentioned aparticular type of injection with some other medicines for the treatment purpose. The injection is given for 21 days, which costs about 9,000 rupees per day. According to Dr HetalMarfatia, Professor and Head of the ENT department, KEM hospital, Mumbai, nearly 2 to 3 mucormycosis infected patients werecoming to the hospital daily for their health checkups and many amongthem did not belong to Mumbai, and were coming from outside for the treatment. He also said that the treatment expense of this mucormycosisinfection is comparatively more, so it is not possible for everyone to afford it. Dr HetalMarfatia shared one incident of a 29-years old patient in rural Maharashtra, who lost his vision completely due to mucormycosis. She suggested that healthy dietary habits and regular exercise are very helpful to stay fit and poor food habits adversely affect the immunity of the host. ${ }^{32}$ Associate Professor of the Ahmedabad based BJ Medical College and Civil Hospital, Dr Kalpesh Patel said to the news agency ANI that the ENT division of their hospital diagnosed 67 mucormycosis infected patients during the last 20 days. Out of all the cases, they weregoing to operate 45 severely ill patients, performing about five to seven operations daily. Dr Kalpesh Patel said that six mucormycosis cases were reported in their hospital for the past two days only. ${ }^{42}$

NitiAayog disagreed with the fact that mucormycosis, black fungus infection is a "big outbreak" in India. VK Paul, Member (Health) of Niti Aayog elaborately confirmed that the black fungal infection is not at all a big issue. ${ }^{29}$

\section{Preventive Measures}

Early diagnosis of the fungal infection and minimisation of underlying risks are very essential to prevent the infection from spreading to the whole body. Indian Council of 
Medical Research mentioned some essential points in their guidelines to reduce the rate of mucormycosis infection such as management of hyperglycemic state after recovery from COVID-19 infection or control of diabetes and diabetic ketoacidosis, appropriate use of steroids, antibiotics, or antifungals (correct duration and doses of drugs) during COVID-19 treatment, and usage of sterile water in a humidifier during oxygen support. ${ }^{36}$ Surgical debridement of infected necrotic tissues is one of the primary and effective treatment procedures of mucormycosis infection to reduce the spreading rate. Administration of antifungal therapy (amphotericin B) intravenously is also considered as a firstline therapy ${ }^{16}$ by considering the current amphotericin $B$ demand and shortage problem across India, five companies such as Alembic Pharmaceuticals, NatcoPharma, Emcure Pharmaceuticals, Lyca Pharmaceuticals, and Gufic Biosciences are manufacturingamphotericin $B$, before that in India, only companies such as Life Care, Sun Pharma, and Cipla were producing the antifungal drugs, and Bharat Serums, and Vaccine, BDR Pharma, Mylan, were producing amphotericin $\mathrm{B}$ liposomal injection. ${ }^{37}$ When oxygen support is mandatory for COVID-19 positive patients, it is essential to make sure that the humidifier is in the right condition that means out of the water leakage. One major point about the usage of steroid drugs is that it should use rationally and appropriately to avoid its long-term adverse health effect. ${ }^{45}$ To prevent mucormycosis, general people should avoid visiting any kind of construction dusty sites.People should maintain their minimum hygiene level including washing hands, scrub bath thoroughly, use shoes, longsleeved shirts, long trousers, and gloves during handling soil, manure, and moss. ${ }^{23}$

\section{Latest Guidelines on Different Treatment Therapies of Mucormycosis in India}

Recently Indian Council of Medical Research (ICMR) stated that there are many other treatment therapies (supplementary medicines) along with amphotericin B and these medications can also decrease the toxicity level of amphotericin B. Liposomal amphotericin B is mainly prescribed for patients with mucormycosis infection in their brain and another one, amphotericin B deoxycholate is nephrotoxic. ${ }^{24}$ For clinical treatment, some essential measures like insertion of central catheter (PICC line) peripherally, adequate systemic hydration, administration of normal saline IV before antifungal amphotericin B administration, antifungal treatment for minimum 4-6 weeks, and thoroughly monitoring of the infected patients to detect drugs' responses and disease progression state are also advised by ICMR. ${ }^{36}$ Normally recommended duration of steroid medication is near about ten days and recommended doses of corticosteroids like dexa, prednisolone, and methylprednisolone are $6 \mathrm{mg}, 40 \mathrm{mg}$, and $32 \mathrm{mg}$ respectively in a day. Special monitoring was suggestedfor the patients with other related comorbidities including autoimmune diseases, kidney disease, liver disease, and malignancies. ${ }^{19}$ Mucormycosis guidelines on 17 May 2021 by The Directorate General of Health Services, Ministry of Health \& Family Welfare, indicated some effective diagnosis methods like $\mathrm{KOH}$ staining and microscopy, histopathology of debrided tissue and culture, and MALDITOF. The guideline recommended an initial $5 \mathrm{mg} / \mathrm{kg}$ body weight dose of liposomal amphotericin B and in case of central nervous system involvement dose is $10 \mathrm{mg} / \mathrm{kg}$ body weight. Amphotericin B vial contains $50 \mathrm{mg}$ of drug and is usedafter dilution in $5 \%$ or $10 \%$ dextrose. Oral posaconazole treatment is usually started after amphotericin B therapy. The recommended dose of posaconazole medication is $300 \mathrm{mg}$ delayed-release tablets two times a day for the first treatment day followed by $300 \mathrm{mg}$ delayed-release tablets per day for the remaining treatment period. Another medication isavuconazolecan also be effective. The dose of isavuconazolefor mucormycosis infection is $200 \mathrm{mg}$ tablet trice in a day for the initial two days of treatment and after that $200 \mathrm{mg}$ per day. In case of unavailability of liposomal amphotericin $B$ and normal kidney function, conventional amphotericin B also called deoxycholateamphotericin B can be recommended (dose $=1-1.5 \mathrm{mg} / \mathrm{kg}$ body weight). ${ }^{15}$ Mucormycosis cases specially rhinocerebral infection and infection with skin, and soft tissue related disease required surgical treatment. ${ }^{10,40}$ Adjunctive therapy is to reverse the immune-suppressed condition of the patients. ${ }^{3}$ Hyperbaric oxygen treatment can improve oxygen pressure, help to maintain neutrophils activities in the human body, and ensure amphotericin B activity against fungal infection. Optimum oxygen pressure in the body exhibits wound healing after surgical debridement and reduces fungal growth. Many studies mentioned iron chelators as adjunctive therapy in mucormycosis infection because iron chelators can stop fungal cell growth by decreasing essential iron concentration for their growth. Many other adjunct therapies use interferon- $\gamma$ or granulocyte colonystimulating factor which up-regulated granulocyte functions to inhibit Mucorales. ${ }^{39}$

\section{Antifungal Drugs}

\section{Amphotericin B}

In 1956, Donovick, Stout, and Gold, Pagano isolated this drug from a soil sample for the first time. In 1959, the drug got a license as a therapeutic agent, and finally, in 1960, this drug became commercially available as Fungizone ${ }^{\circledR}$ (amphotericin B colloidal suspension). From a local mycotic infections medication, gradually it became an essential antifungal therapy and for the past 60 years, this drug treatment has maintainedits position as effectively asbefore. ${ }^{5}$ The cell membrane of fungi consists of ergosterol, which binds with the hydrophobic part of amphotericin 
B after amphotericin B administration to fungus-infected patients. Ergosterol- amphotericin B binding forms ion channels and pores, which leads to monovalent cations and protons loss from the fungal cell. Gradually this loss confirmed concentration-dependent and depolarisation associated cell destruction. Amphotericin B deoxycholate, also called conventional amphotericin $B$, comes under polyene class of antifungals. Common amphotericin $B$ deoxycholate related side effects are decrease in the level of magnesium and potassium concentration in the human body, general fever, anaphylaxis, renal system disturbance (due to renal toxicity), demyelinating encephalopathy (for bone marrow transplanted patients), normocytic and normochromic anaemia (due to long term usage). ${ }^{5}$ The European Confederation of Medical Mycology (ECMM) and The European Conference on Infections in Leukemia (ECIL) approved liposomal amphotericin B for first-line mucormycosis infection therapy in adults and amphotericin $B$ lipid complex along with liposomal amphotericin B for children. ${ }^{3} \mathrm{~A}$ study by NaeimiEshkaletiet al. confirmed the positive results of combination therapy of amphotericin B and atorvastatin against Rhizopusoryzae strains. ${ }^{26}$ Another experimental study evaluated the effectiveness of posaconazole ( $40 \mathrm{mg}$ of posaconazole per kg body weight/ day) and amphotericin B (0.8 mg of amphotericin $/ \mathrm{kg} /$ day) against six species of Mucorcircinelloides in mice model. ${ }^{35}$ Ascientific study cleared that liposomal amphotericin $B$ and posaconazole treatments can successfully reduce fungal cell number (Mucorales) in the brain, and infection severity, and can improve survival time in diabetic ketoacidotic as well as cyclophosphamide-cortisone acetate treated mice group than placebo mice group. ${ }^{21}$ One multicentred, placebocontrolled, double-blinded clinical trial failed to conclude any statement regarding this combination therapy due to study population imbalance between control (received liposomal amphotericin B plus placebo) and treatment group. ${ }^{41}$

Ibrahim et al. conducted one in vivo study and revealed that a high dose of liposomal amphotericin B (7.5 mg per kg body weight twice a day) contributes higher efficacy against fungal infection than the control group of mice as well as amphotericin $B$ deoxycholate treated mice group $\left(0.5 \mathrm{mg} / \mathrm{kg}\right.$ body weight twice in a day). ${ }^{17} \mathrm{~A}$ study by Ibrahim et al. suggested that amphotericin $B$ lipid complex is equally effective as liposomal amphotericin B in the case of neutropenic mice model only not in diabetic ketoacidosismice model. ${ }^{18}$

\section{Isavuconazole}

Isavuconazole is one kind of azoles which has a wide range of lytic activity against moulds like Mucorales and yeasts. Itgot approval as a mucormycosis treatment therapy in the year 2015 in the United States and Europe.
Itcan be administered in two distinct forms, one is an oral formulation and another one is an intravenous formulation. Ithas some advantages such as this drug can decrease QT (waves in electrocardiogram), drug interaction possibilities by decreasing cytochrome P450 isoenzymes interaction and maintain linear pharmacokinetics. For isavuconazoleadministration through IV formulation, cyclodextrin is not at all required in IV formulation, which can reduce the chance of nephrotoxicity because cyclodextrin is nephrotoxic. In the case of isavuconazoledrug ingestion, proper dose management is not required for patients with obesity, kidney, liver problems, and oral isavuconazoledrug bioavailability is also highly satisfactory. ${ }^{3}$ Isavuconazole suppressed fungal cytochrome P450 dependent 14-alpha-lanosterol demethylase enzyme that ceases fungal ergosterol production from lanosterol, and depleting ergosterol concentration in the fungal cell membrane leads to cell death gradually. ${ }^{27}$ One singlearm open-label trial, VITAL study was conducted from April 2008 to June 2013, and the study confirmed the efficacy of isavuconazole drug for primary mucormycosis treatment and also suggests that isavuconazole can be an alternative therapy for the patients who have amphotericin $B$ intolerance. ${ }^{22}$ Combination therapy (isavuconazole and micafungin) treated mice effectively and improved survival rate as compared to theplacebo group but compared to monotherapy, its activity was very low. ${ }^{14}$ Evaluation of a case study of a 45-year-old man showed that the patient was rhinocerebralmucormycosis infected and the infection occurred by Rhizopusoryzae. Due to some medical problems, liposomal amphotericin B and posaconazole drug treatment were not possible. The patient was in isavuconazole salvage therapy, and was able to tolerate this drug. Even after discharge from hospital, the follow-up study confirmed that the patient had afungal infectious disease for the nexttwo years. ${ }^{13}$ In vivo experiment with cortisone acetate or cyclophosphamide treated Rhizopusdelemar fungusinfected mice confirmed the fact that isavuconazole in higher concentration increased survival and lowered tissue burden due to fungal infection which was as effective as amphotericin B therapy. ${ }^{20}$

\section{Posaconazole}

Posaconazole therapy is also very promising as a salvage treatment, which is one of the most promising secondline treatments for mucormycosis. ${ }^{1,40}$ Additionally many advantages like fungicidal potentiality, fewer adverse effects on human health, and ingestible through oral route, low cost compared to amphotericin B drug makes posaconazole drug therapy as a super suitable option for any kind of mucormycosis infections. As per this scientific journal, only lyophilised amphotericin B (3 g dose) drug treatment costs near about 200,000-300,000 INR for only one month whereas oral posaconazole drug therapy costs 
approximately 180,000 INR only for three months. ${ }^{33}$

\section{Conclusion}

This review article reveals thatpoor host immune response during COVID-19 infection can elevate the chances of secondary mucormycosis infection. COVID-19 positive patients with oxygen support are more vulnerable to fungal infection due to humidifier containing water into the oxygen support system, which exhibits the spreading chances of black fungus infection and spreading to the brain might be fatal for an individual. Due to its high infection rate and severity, some states and Union Territories declared mucormycosis infection as an epidemic condition. The review article also showed the usage and advantages of some popular therapeutic interventions likeLiposomal amphotericin B antifungal therapy, isavuconazole, Posaconazoletherapy, combination therapy, and adjunctive therapy to prevent the infection. Moreover, this article supports the fact that health care professionals should remember some important points including avoidingtoo early usage of corticosteroids, avoiding excessive use of steroids, and last but not the least,avoidinglong term use of steroid medication while dealing with oral or intravenous corticosteroids.

\section{Acknowledgements}

The author would like to express gratitude to his colleagues atHiralaMazumdarMemorialCollege for Women, Kolkata for being immensely cooperative.

\section{Ethics Approval and Consent}

This study has nothing to do with human and animal testing.

\section{Funding Declaration}

The authors didnot receive any financial support for the said research project from any organisation.

\section{Conflict of Interest: None}

\section{References}

1. Athanasiadou KI, Athanasiadis DI, Constantinidis J, Anastasiou A, Roilides E, \&Papakonstantinou E. Successful treatment of rhinoorbitalmucormycosis due to Rhizopusarrhizus with liposomal amphotericin B, posaconazole and surgical debridement in a child with neuroblastoma. Med Mycol Case Rep.2019;25:10-4. [PubMed] [Google Scholar]

2. The Economic Times [Internet].Black fungus: How infection starts, death rate, treatment, medicine \& other key things to know; 2021. Accessed on $1^{\text {st }}$ June, 2021. Available from: https://economictimes. indiatimes.com/news/et-explains/black-fungus-howinfection-starts-death-rate-treatment-medicine-otherkey-things-to-know/articleshow/82796816.cms

3. Brunet K, Rammaert B. Mucormycosis treatment:
Recommendations, latest advances, and perspectives. J Mycol Med. 2020;30(3):101007. [PubMed] [Google Scholar]

4. BusinessLine [Internet]. Govt restricts export of Amphotericin-B drug; 2021 Jun 1. Accessed on $10^{\text {th }}$ June, 2021. Available from: https://www. thehindubusinessline.com/news/national/ govt-restricts-export-of-amphotericin-b-drug/ article34702010.ece

5. Cavassin FB, Baú-Carneiro JL, Vilas-Boas RR, QueirozTelles F. Sixty years of Amphotericin B: an overview of the main antifungal agent used to treat invasive fungal infections. Infec Dis Ther. 2021;10(1):115-47. [PubMed] [Google Scholar]

6. Centers for Disease Control and Prevention [Internet]. Where Mucormycosis Comes From; [cited 2021 May 5]. Available from: https://www.cdc.gov/ fungal/diseases/mucormycosis/causes.html

7. Centers for Disease Control and Prevention[Internet]. Mucormycosis; [cited 2021 May 5]. Available from: https://www.cdc.gov/fungal/diseases/mucormycosis/ index.html

8. NORD [Internet].Mucormycosis; [cited 2021 May 5]. Available from: https://rarediseases.org/rare-diseases/ mucormycosis/

9. Centers for Disease Control and Prevention[Internet]. Symptoms of mucormycosis; [cited 2021 May 5]. Available from: https://www.cdc.gov/fungal/diseases/ mucormycosis/symptoms.html

10. Cornely OA, Alastruey-Izquierdo A, Arenz D, Chen SC, Dannaoui E, Hochhegger B, Hoenigl M, Jensen HE, Lagrou K, Lewis RE, Mellinghoff SC, Mer M, Pana ZD, Seidel D, Sheppard DC, Wahba R, Akova M, Alanio A, Al-Hatmi AM, Arikan-AkdagliS, BadaliH, Ben-Ami R, BonifazA, Bretagne S, CastagnolaE, ChayakulkeereeM, Colombo AL, Corzo-León DE, DrgonaL, GrollAH, Guinea J, HeusselCP, Ibrahim AS, KanjSS, KlimkoN, LacknerM, LamothF, LanternierF, Lass-FloerIC, Lee DG, LehrnbecherT, LmimouniBE, Mares M, MaschmeyerG, MeisJF, MeletiadisJ, Morrissey CO, NucciM, OladeleR, Pagano L, PasqualottoA, Patel A, RacilZ, Richardson M, RoilidesE, RuhnkeM, SeyedmousaviS, SidharthanN, Singh N, SinkoJ, SkiadaA, SlavinM, SomanR, SpellbergB, Steinbach W, Tan BH, UllmannAJ, VehreschildJJ, VehreschildMJ, Walsh TJ, White PL, WiederholdNP, ZaoutisT, ChakrabartiA;Mucormycosis ECMM MSG Global Guideline Writing Group. Global guideline for the diagnosis and management of mucormycosis: an initiative of the European Confederation of Medical Mycology in cooperation with the Mycoses Study Group Education and Research Consortium. Lancet Infect Dis.2019;19(12):e405-e421. [PubMed] [Google Scholar] 11. The Weather Channel[Internet]. COVID-19 India FAQs: 
What is Black Fungus, How It Spreads, Who It Can Infect and More. Accessed on $5^{\text {th }}$ June, 2021. Available from: https://weather.com/en-IN/india/coronavirus/ news/2021-05-07-covid-19-faqs-what-is-black-fungushow-it-spreads-and-infects

12. Deccan Herald [Internet]. Covid-19 crisis: Which states in India have reported the highest number of mucormycosis cases?;2021 May 22. Accessed on $2^{\text {nd }}$ June, 2021. Available from: https://www.deccanherald. com/national/covid-19-crisis-which-states-in-indiahave-reported-the-highest-number-of-mucormycosiscases-988666.html

13. Ervens J, Ghannoum M, Graf B, Schwartz S. Successful isavuconazole salvage therapy in a patient with invasive mucormycosis. Infection.2014;42(2):429-32. [PubMed] [Google Scholar]

14. Gebremariam T, Wiederhold NP, Alqarihi A, Uppuluri P, Azie N, Edwards JE, Ibrahim AS. Monotherapy or combination therapy of isavuconazole and micafungin for treating murine mucormycosis. J AntimicrobChemother. 2017;72(2):462-6. [PubMed] [Google Scholar]

15. The Directorate General of Health Services, Ministry of Health \& Family Welfare[Internet]. Guideline for management of Mucormycosis in Covid - 19 patients; 2021. Accessed on $5^{\text {th }}$ June, 2021. Available from: https://dghs.gov.in/WriteReadData/ News/202105171119301555988MucormycosismanagementinCovid-19.pdf

16. Hernández JL, Buckley CJ. Mucormycosis.StatPearls; 2021. [PubMed] [Google Scholar]

17. Ibrahim AS, Avanessian V, Spellberg B, Edwards JE. Liposomal Amphotericin B, and not Amphotericin B Deoxycholate, improves survival of diabetic mice infected with Rhizopusoryzae. Antimicrob Agents Chemother.2003;47(10):3343-4. [PubMed] [Google Scholar]

18. Ibrahim AS, Gebremariam T, Husseiny MI, Stevens DA, Fu Y, Edwards JE, Spellberg B. Comparison of Lipid Amphotericin B preparations in treating murine zygomycosis. Antimicrob Agents Chemother.2008;52(4):1573-6. [PubMed] [Google Scholar]

19. Kapur M [Internet]. Why does India have so many cases of post-Covidmucormycosis?Quartz; 2021 May 24. Accessed on $1^{\text {st }}$ June, 2021. Available from: https:// qz.com/india/2012257/why-india-has-so-many-casesof-mucormycosis-or-black-fungus/

20. Luo G, Gebremariam T, Lee H, Edwards JE, Kovanda L, Ibrahim AS. Isavuconazoletherapy protects immunosuppressed mice from mucormycosis. Antimicrob Agents Chemother.2014;58(4):2450-3. [PubMed] [Google Scholar]

21. Luo G, Gebremariam T, Lee H, French SW, Wiederhold NP, Patterson TF, Filler SG, Ibrahim AS. Efficacy of Liposomal Amphotericin B and Posaconazole in intratrachealmodels of murine mucormycosis. Antimicrob Agents Chemother.2013;57(7):3340-7. [PubMed] [Google Scholar]

22. Marty FM, Ostrosky-Zeichner L, Cornely OA, Mullane KM, Perfect JR, Thompson GR, Alangaden GJ, Brown $J M$, Fredricks DN, Heinz WJ, Herbrecht R, Klimko N, Klyasova G, Maertens JA, Melinkeri SR, Oren I, Pappas PG, Ráčil Z, Rahav G, Santos R, Schwartz S, VehreschildJJ, Young JA, ChetchotisakdP, JaruratanasirikulS, KanjSS, EngelhardtM, KaufholdA, Ito M, Lee M, Sasse C, Maher RM, ZeiherB, VehreschildMJ; VITAL and FungiScopeMucormycosis Investigators. Isavuconazole treatment for mucormycosis: a single-arm open-label trial and case-control analysis. Lancet Infect Dis.2016;16(7):82837. [PubMed] [Google Scholar]

23. Mascarenhas A [Internet]. Explained: What is mucormycosis or 'black fungus' in Covid-19 patients, its symptoms and treatment. The Indian Express; 2021 Jun 8. Accessed on $8^{\text {th }}$ June, 2021Available from: https:// indianexpress.com/article/explained/mucormycosis-in-covid-patients-fungal-infections-7308721/

24. Mathur A [Internet]. Amphotericin B not only medication available for black fungus: ICMR tells Delhi HC. India Today; 2021 Jun 4. Accessed on $7^{\text {th }}$ June, 2021. Available from: https://www.indiatoday.in/coronavirus-outbreak/story/amphotericin-b-not-only-medication-available-black-fungus-icmr-delhi-hc-1810831-2021-06-04

25. Mehta S, Pandey A. Rhino-Orbitalmucormycosisassociated with COVID-19. Cureus. 2020 Sep;12(9):e10726. [PubMed] [Google Scholar]

26. EshkaletiMN, KordbachehP, HashemiSJ, FalahatiM, ZainiF, MirhendiH, SafaraM, HosseinpoorL. In vitro activity of Amphotericin B in combination with statins against clinical and environmental Rhizopusoryzae Strains. Iran J Public Health.2019 May;48(5):943-8. [PubMed] [Google Scholar]

27. Natesan SK, Chandrasekar PH. Isavuconazole for the treatment of invasive aspergillosis and mucormycosis: current evidence, safety, efficacy, and clinical recommendations. Infect Drug Resist. 2016;9:291-300. [PubMed] [Google Scholar]

28. News18 [Internet]. Black Fungus Kills 8 Covid-Recovered Patients in Maharashtra; Gujarat Too Reports Cases; 2021 May 8. Accessed on $5^{\text {th }}$ June, 2021. Available from: https://www.news18.com/news/india/black-fungus-8covid-survivors-die-in-maha-gujarat-reports-50-casesseveral-lose-eyesight-3719456.html

29. LiveMint [Internet]. Black fungus detected in Covid-19 patients, not 'big outbreak', says NitiAayog;2021 May 7. Accessed on $5^{\text {th }}$ June, 2021. Available from: https:// www.livemint.com/news/india/black-fungus-detected-in-covid-19-patients-not-big-outbreak-says-niti- 
aayog-11620402576357.html

30. Noor A, Preuss CV. Amphotericin B.StatPearls;2021. [PubMed] [Google Scholar]

31. Priya P, Ganesan V, Rajendran T, Geni VG. Mucormycosis in a tertiary care centerin South India: A 4-year experience. Indian J Crit Care Med.2020;24(3):168-71. [PubMed] [Google Scholar]

32. The Print [Internet]. At least 8 Covid survivors die of black fungus 'mucormycosis' in Maharashtra. Accessed on $2^{\text {nd }}$ June, 2021. Available from: https://theprint.in/ health/at-least-8-covid-survivors-die-of-black-fungusmucormycosis-in-maharashtra/654924/

33. Rai S, Yadav S, Kumar D, Kumar V, Rattan V. Management of rhinomaxillarymucormycosis with Posaconazole in immunocompetent patients. J Oral BiolCraniofac Res.2016;6. [PubMed] [Google Scholar]

34. Raut A, Huy NT. Rising incidence of mucormycosis in patients with COVID-19: another challenge for India amidst the second wave? Lancet Respir Med. 2021;9(8):e77.[PubMed] [Google Scholar]

35. Salas V, Pastor FJ, Calvo E, Alvarez E, Sutton DA, Mayayo E, Fothergill AW, Rinaldi MG, Guarro J. In Vitroand in vivo activities of Posaconazole and Amphotericin B in a murine invasive infection by mucorcircinelloides: poor efficacy of Posaconazole. Antimicrob Agents Chemother.2012;56(5):2246-50. [PubMed] [Google Scholar]

36. ICMR [Internet]. Evidence based advisory in the time of COVID-19: screening, diagnosis \&management of mucormycosis; [cited 2021 Jun 8]. Available from: https://www.icmr.gov.in/pdf/covid/techdoc/Mucormycosis_ADVISORY_FROM_ICMR_In_COVID19_time.pdf

37. India Infoline [Internet]. DCGI approves 5 more pharma companies to produce Amphotericin B injection in India. Accessed on $5^{\text {th }}$ June, 2021. Available from: https:// www.indiainfoline.com/article/news-top-story/dcgi-approves-5-more-pharma-companies-to-produce-amphotericin-b-injection-in-india-121052100211_1.html

38. Sharma S, Grover M, Bhargava S, Samdani S, Kataria T. Post coronavirus disease mucormycosis: a deadly addition to the pandemic spectrum. J Laryngol Otol.2021;135(5):442-7. [PubMed] [Google Scholar]

39. Sipsas NV, Gamaletsou MN, Anastasopoulou A, Kontoyiannis DP. Therapy of Mucormycosis. J Fungi.2018;4(3):90. [PubMed] [Google Scholar]

40. Skiada A, Lanternier F, Groll AH, Pagano L, Zimmerli S, Herbrecht R, Lortholary O, Petrikkos GL; European Conference on Infections in Leukemia. Diagnosis and treatment of mucormycosis in patients with hematological malignancies: guidelines from the 3rd European Conference on Infections in Leukemia (ECIL 3). Haematologica.2013;98(4):492-504. [PubMed] [Google Scholar]

41. Spellberg B, Ibrahim AS, Chin-Hong PV, Kontoyiannis
DP, Morris MI, Perfect JR, Fredricks D, Brass EP. The Deferasirox-AmBisome Therapy for Mucormycosis (DEFEAT Mucor) study: a randomized, double-blinded, placebo-controlled trial. J AntimicrobChemother.2012;67(3):715-22. [PubMed] [Google Scholar]

42. NDTV [Internet]. Gujarat hospital reports rise in Covidcases with black fungus infection. Accessed on $2^{\text {nd }}$ June, 2021. Available from: https://www.ndtv.com/ india-news/coronavirus-black-fungal-infection-gujarat-hospital-reports-more-covid-induced-black-fungus-cases-2437714

43. The Economic Times [Internet]. Maharashtra to get 60,000 vials of drug for mucormycosis from June 1 through global tender: Rajesh Tope. Accessed on $29^{\text {th }}$ May, 2021. Available from: https://economictimes.indiatimes.com/news/india/maharashtra-to-get-60000vials-of-drug-for-mucormycosis-from-june-1-throughglobal-tender-rajesh-tope/articleshow/82940289. cms?from $=m d r$

44. Times Now News [Internet]. Mucormycosis, black fungus, raises its head in Delhi hospital: All you need to know about this fatal infection. Accessed on $29^{\text {th }}$ May, 2021. Available from: https://www.timesnownews. com/health/article/mucormycosis-black-fungus-raises-its-head-in-delhi-hospital-all-you-need-to-knowabout-this-fatal-infection/753987

45. LiveMint [Internet].As black fungus cases rise in India, AlIMS chief lists key factors to prevent mucormycosis; 2021 May 21. Accessed on $2^{\text {nd }}$ June, 2021. Available from: https://www.livemint.com/news/india/as-mucormycosis-cases-rise-in-india-aiims-director-lists-keyfactors-to-prevent-black-fungus-11621592318715.html

46. Rema Nagarajan / TNN / Updated: May 30, 2021. Covid-19: Shortage of black fungus drug Amphotericin- $B$ looming: India News - Times of India. Accessed on $28^{\text {th }}$ May , 2021The Times of India. https://timesofindia. indiatimes.com/india/covid-19-shortage-of-black-fungus-drug-looming/articleshow/83079300.cms. 